\title{
Notes on the vocalizations of Grey-cheeked Fulvetta (Alcippe morrisonia)
}

Peter Boesman

In the following we briefly analyze and compare voice of the different races of Grey-cheeked Fulvetta (Alcippe morrisonia). We also try to quantify the extent of any vocal differences using the criteria proposed by Tobias et al. (2010), as a support for taxonomic review. We have made use of sound recordings available on-line from Xeno Canto (XC) and Macaulay Library (ML).

Song consists of a short whistled phrase, often followed by some nasal notes. Comparison of sonograms of the different groups:

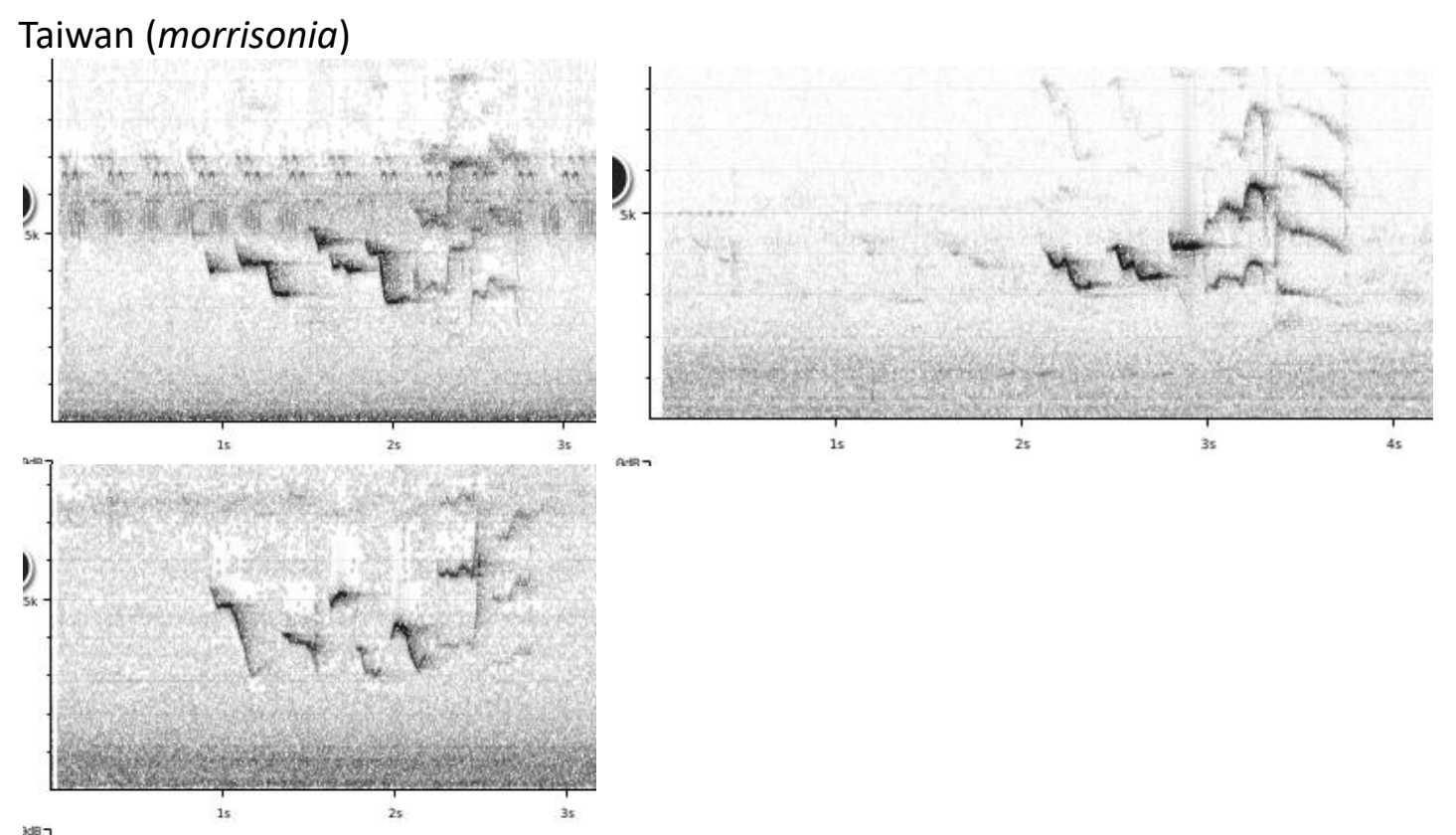

David's Fulvetta (davidi, schaefferi)

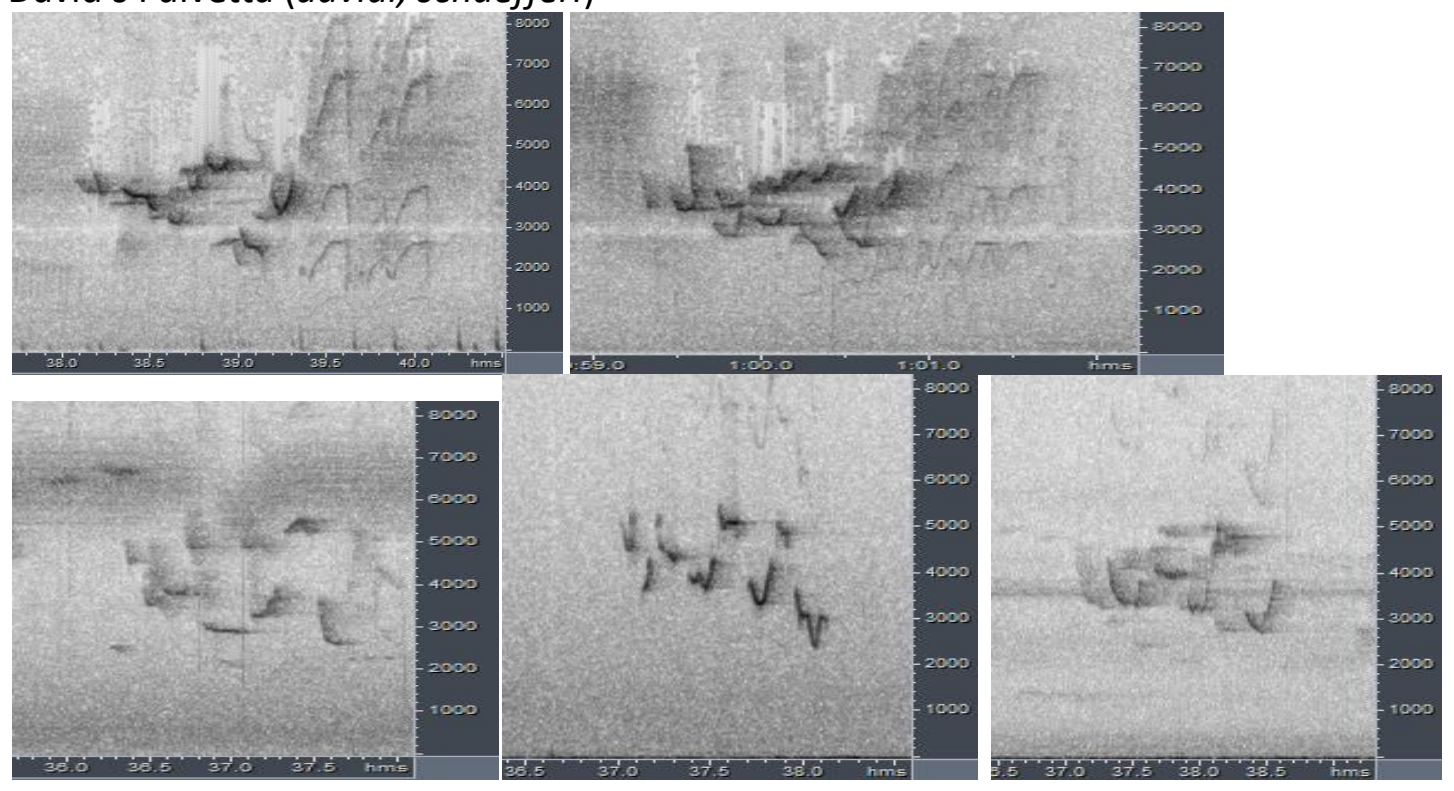




\section{HANDBOOK OF THE \\ BIRDSPF THE WORLD \\ Alue}

\section{ORNITHOLOGICAL NOTES}

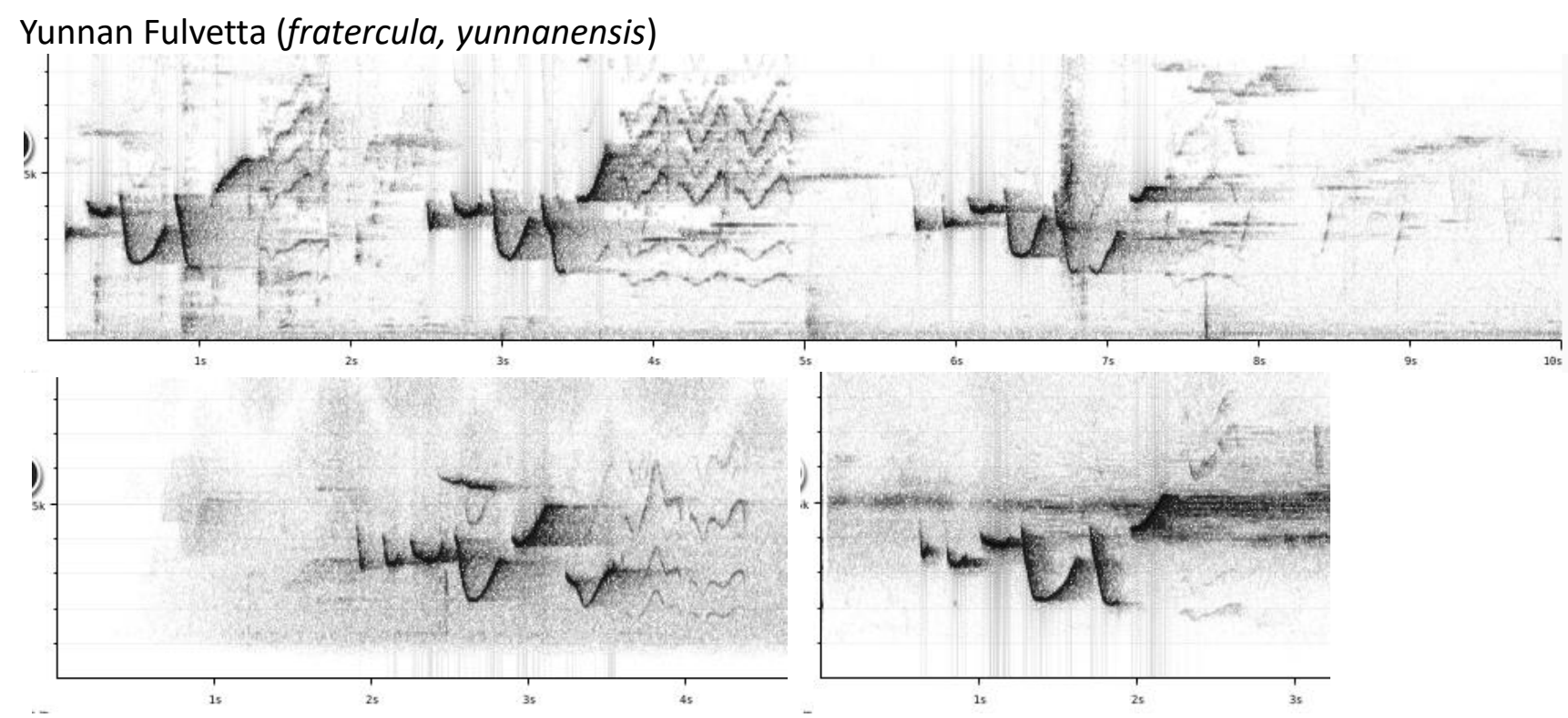

Huet's Fulvetta (hueti, rufescentior)
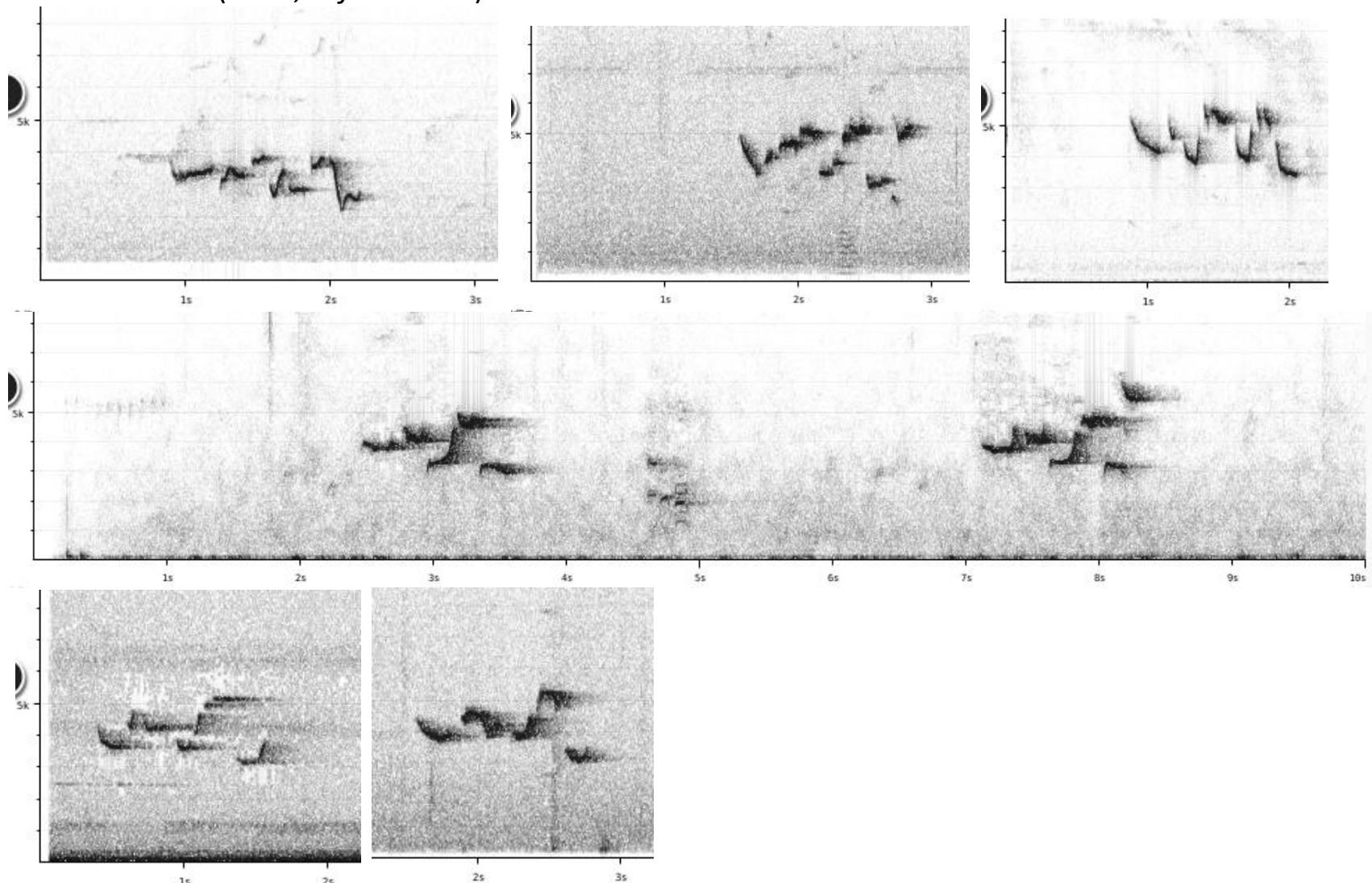

From the above examples, it is quite clear that whistles in song of the Yunnan group are the most distinctive, some of which are longer in duration and covering a larger freq. range than in any other group.

The whistled phrase of other groups can't be safely told apart, all basic sound parameters being similar. Note shape in song of David's group slightly different from Taiwan and Huet's group, less irregular with more simple shapes, but there is nevertheless quite some overlap. 

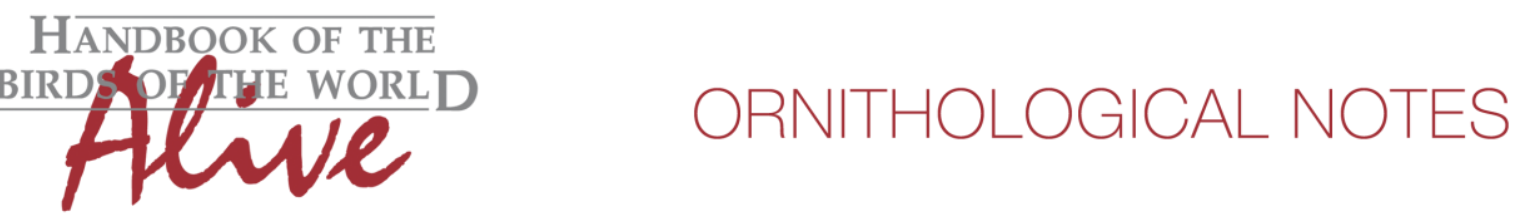

The second part of the song, the subdued nasal scolding notes, seems to be present about always in Taiwan and Yunnan group, only sometimes in David's group and apparently hardly or not in Huet's group.

Based on the available recordings, vocal differences could be quantified as follows:

Yunnan group vs all others: estimated vocal score $1+1=2$ based on note shape (or duration) and 'max. freq. range of single note'.

Huet's Fulvetta vs all others: estimated vocal score 1-2 based on apparent absence of second nasal part in song.

David's group vs Taiwan group: estimated vocal score 0-1 based on slightly different note shape.

Vocal differences between all groups are thus rather minor, with Yunnan group somewhat more distinctive.

This note was finalized on 13th April 2016, using sound recordings available on-line at that moment. We would like to thank in particular the many sound recordists who placed their recordings for this species on XC and ML:.

\section{References}

Tobias, J.A., Seddon, N., Spottiswoode, C.N., Pilgrim, J.D., Fishpool, L.D.C. \& Collar, N.J. (2010). Quantitative criteria for species delimitation. Ibis 152(4): 724-746.

\section{Recommended citation}

Boesman, P. (2016). Notes on the vocalizations of Grey-cheeked Fulvetta (Alcippe morrisonia). HBW Alive Ornithological Note 274. In: Handbook of the Birds of the World Alive. Lynx Edicions, Barcelona. (retrieved from http://www.hbw.com/node/1251715 on 6 October 2016). 